\title{
Wiesner nevus
}

\author{
Gerardo Ferrara MD, Maria Teresa Corradin MD
}

Cite as: CMAJ 2017 January 9;189:E26. doi: 10.1503/cmaj.160049

A 48-year-old woman presented with a papule of the left alar groove (Figure 1) that had been growing slowly for about two years. Clinical features (telangiectatic surface) suggested nodular basal cell carcinoma. Physical examination was otherwise normal.

Histopathologic examination showed a dome-shaped neoplasm, with dermal nests infiltrated by lymphocytes comprising epithelioid cells showing oval- to kidney-shaped nuclei and abundant eosinophilic, often inclusionlike, cytoplasms. There were no atypical features (i.e., large sheets of cells, perineural/perivascular/periadnexal involvement, confluent pleomorphism, mitoses). Neoplastic cells showed loss of the constitutive nuclear immunostaining for BAP1 protein and were positive for the VE1 (anti-BRAFV600E mutated protein) antibody (Appendix 1, available at www.cmaj.ca/lookup/suppl/ doi:10.1503/cmaj.160049/-/DC1). All these features were consistent with a Wiesner nevus.

Biallelic inactivating mutations of the $B A P 1$ tumour suppressor gene on chromosome 3p21.1 and loss of nuclear immunoreactivity for the BAP1 protein are characteristic of BAPomas, ${ }^{1}$ which represent $0.005 \%$ of all excised melanocytic tumours. These range from completely benign (e.g., Wiesner nevus), ${ }^{2}$ as in this patient, to melanocytic borderline atypical intradermal tumours ${ }^{3}$ and to overtly malignant tumours. A BRAFV600E mutation, detectable with the VE1 immunostain, is present in about $70 \%$ of BAPomas. ${ }^{3}$

Wiesner nevus grows slowly, and no further action is necessary after excision of the nevus. However, the patient should be checked for the presence of multiple fibroma-like nevi. These nevi are the hallmarks of the uncommon familial tumour predisposition syndrome (Online Mendelian Inheritance in Man; OMIM:614327) caused by germline BAP1 inactivating mutations, which is associated with atypical Spitz tumours/melanocytic borderline atypical intradermal tumours, cutaneous and uveal melanoma, and internal neoplasms (e.g., mesothelioma, renal clear cell carcinoma, lung adenocarcinoma, squamous cell carcinoma of the head and neck, breast carcinoma, myelodysplasia, medulloblastoma and meningioma). ${ }^{1,3}$

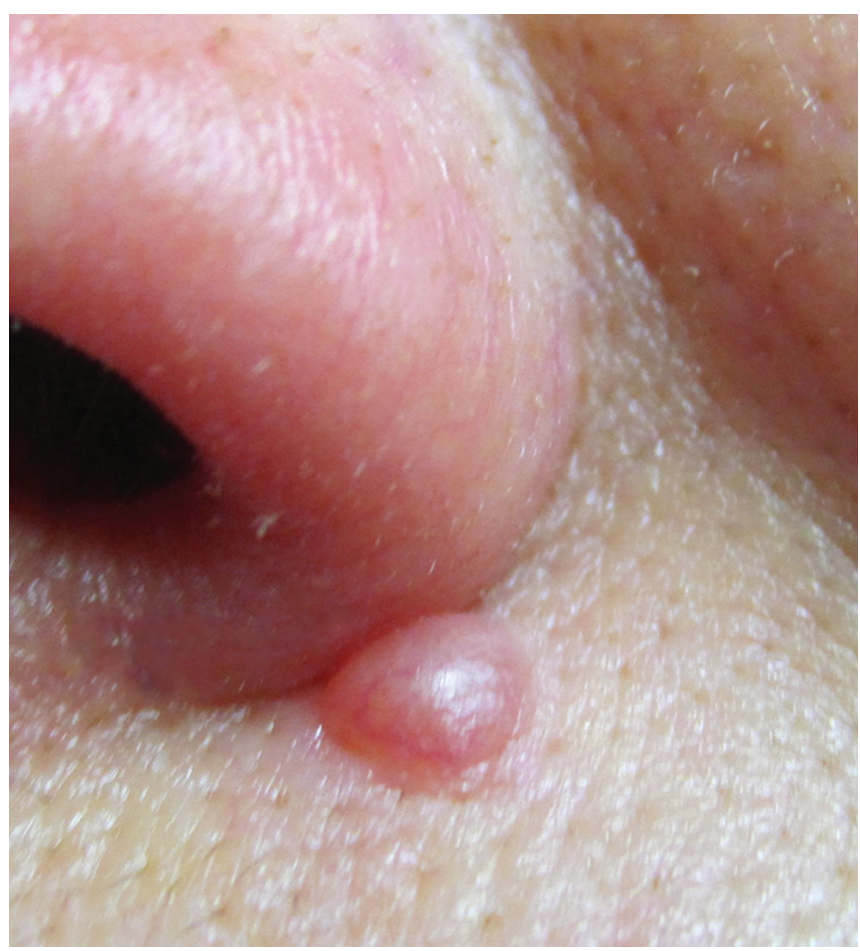

Figure 1: Wiesner nevus on the left alar groove of a 48-year-old woman.

Any cutaneous papulonodular lesion reported to be growing should be excised. If Wiesner nevus is diagnosed histopathologically and is associated with multiple cutaneous (fibroma-like) melanocytic tumours, the patient should receive genetic testing for tumour predisposition syndrome.

\section{References}

1. Wiesner T, Obenauf AC, Murali R, et al. Germline mutations in BAP1 predispose to melanocytic tumors. Nat Genet 2011;43:1018-21.

2. Llamas-Velasco M, Pérez-Gónzalez YC, Requena L, et al. Histopathologic clues for the diagnosis of Wiesner nevus. J Am Acad Dermatol 2014;70:549-54.

3. Yeh I, Mully TW, Wieser T, et al. Ambiguous melanocytic tumors with loss of 3p21. Am J Surg Pathol 2014;38:1088-95.

\section{Competing interests: None declared.}

This article has been peer reviewed.

The authors have obtained patient consent.
Affiliations: Department of Oncology (Ferrara), Anatomic Pathology Unit, Gaetano Rummo General Hospital, Benevento, Italy; Department of Dermatology (Corradin), Santa Maria degli Angeli Hospital, Pordenone, Italy
Acknowledgement: The authors thank Dr. Thomas Wiesner for his suggestions during manuscript preparation.

Correspondence to: Gerardo Ferrara, gerardo.ferrara@libero.it 